\title{
Heart transplant centers with multidisciplinary team show a higher level of chronic illness management - Findings from the International BRIGHT Study
}

\author{
Maan Isabella Cajita, PhD, RN-BC ${ }^{\mathrm{a}, 1}$, Eva Baumgartner, MSN ${ }^{\mathrm{b}, 1}$, Lut Berben, PhD, RN ${ }^{\mathrm{b}}$, \\ Kris Denhaerynck, PhD, RN ${ }^{\mathrm{b}}$, Remon Helmy, MSc ${ }^{\mathrm{b}}$, Sandra Schönfeld, MSN ${ }^{\mathrm{b}}$, \\ Gabriele Berger, MSN ${ }^{\mathrm{b}}$, Christine Vetter, MSN ${ }^{\mathrm{b}}$, Fabienne Dobbels, PhD, MSc ${ }^{\mathrm{b}, \mathrm{c}}$, \\ Cynthia L. Russell, PhD, RN ${ }^{\mathrm{d}}$, Sabina De Geest, PhD, RN ${ }^{\mathrm{b}, \mathrm{c}, *}$, \\ on behalf of the BRIGHT Study Team ${ }^{2}$
}

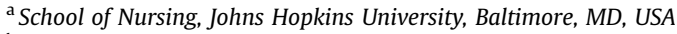

${ }^{\mathrm{b}}$ Institute of Nursing Science, Department of Public Health, Faculty of Medicine, University of Basel, Basel, Switzerland

${ }^{\mathrm{c}}$ Academic Centre for Nursing and Midwifery, Department of Public Health and Primary Care, KU Leuven, Leuven, Belgium

${ }^{\mathrm{d}}$ School of Nursing and Health Studies, University of Missouri-Kansas City, MO, USA

\section{A R T I C L E I N F O}

\section{Article history:}

Received 15 March 2017

Received in revised form

1 May 2017

Accepted 14 May 2017

Available online $\mathrm{xxx}$

\begin{abstract}
A B S T R A C T
Objectives: The objectives of this study were to: (1) explore the proportion of HTx centers that have a multidisciplinary team and (2) assess the relationship between multidisciplinarity and the level of chronic illness management (CIM).

Background: The International Society for Heart and Lung Transplantation (ISHLT) recommends a multidisciplinary approach in heart transplant (HTx) follow-up care but little is known regarding the proportion of HTx centers that meet this recommendation and the impact on patient care. HTx centers
\end{abstract}

Abbreviations: HTx, Heart transplantation; CIM, Chronic Illness Management; BRIGHT, Building Research Initiative Group: Chronic Illness Management and Adherence in Transplantation; PACIC, Patient Assessment of Chronic Illness Care; ISHLT, International Society of Heart and Lung Transplantation; APN, Advanced Practice Nurse; TNS, Transplant Nurse Specialist; Tx, Transplantation.

Funding: The BRIGHT study is funded by research grants of the International Transplant Nurses Society (ITNS) in 2008, the International Society for Heart and Lung Transplantation (ISHLT) in 2012, the Swiss Academy of Medical Sciences (SAMW) in 2013 as well as by an unrestricted research grant from Astellas Pharma. None of the grants has a grant number. None of the organizations that provided funding has access to the data nor were involved in the preparation of the manuscript.

M.I. Cajita is supported by the NINR Ruth L. Kirschstein National Research Service Award (1 F31 NR015943-02).

Conflict of Interest: None.

* Corresponding author. Institute of Nursing Science, Department Public Health, University of Basel, Bernoullistrasse 28, CH-4056 Basel, Switzerland. Fax: $+41(0) 61$ / 2670955.

E-mail address: sabina.degeest@unibas.ch (S. De Geest).

1 Joint first authors.

2 [The BRIGHT study team consists of: Maria G. Crespo-Leiro (Hospital Universitario À Coruña, La Coruña, Spain); Sandra Cupples (U.S. Department of Veterans Affairs, Veterans Health Administration, Washington, DC, USA); Paolo De Simone (Azienda Ospedaliero - Universitaria Pisana, Ospedale Cisanello, Pisa, Italy); Albert Groenewoud (Astellas Pharma Europe Ltd., UK); Christiane Kugler (Hannover Medical School, Hannover, Germany); Linda Ohler (George Washington University, Washington, DC, USA); Johan Van Cleemput (University Hospitals Leuven, Leuven, Belgium); Alain Jean Poncelet (Cliniques Universitaires Saint - Luc, Brussels,
Belgium); Laurent Sebbag (Hôpital Louis Pradel, Lyon, France); Magali Miche (Hôpital Nord Laennec, Nantes, France); Andrée Bernard (Hôpital Universitaire Pitié - Salpêtrière, Paris, France); Andreas Doesch (University Hospital Heidelberg, Heidelberg, Germany); Ugolino Livi (University Hospital Udine, Udine, Italy); Valentina Manfredini (University of Bologna, Bologna, Italy); Vicens Brossa-Loidi (Hospital de Sant Pau, Barcelona, Spain); Javier Segovia-Cubero (Hospital Puerta de Hierro, Madrid, Spain); Luis Almenar-Bonet (Hospital Universitari i Politècnic La Fe de Valencia, Valencia, Spain); Carmen Segura Saint-Gerons (Hospital Univeritario Reina Sofia, Córdoba, Spain); Paul Mohacsi (University Hospital of Bern, Bern, Switzerland); Eva Horvath (University Hospital Zurich, Zurich, Switzerland); Chery Riotto (Papworth Hospital, Cambridge, UK); Gareth Parry (Freeman Hospital, Newcastle, UK); Ashi Firouzi (Royal Brompton \& Harefield NHS Foundation Trust, London, UK); Stella Kozuszko (Toronto General Hospital, Toronto, Canada); Haissam Haddad (University of Ottawa Heart Institute, Ottawa, ON, Canada); Annemarie Kaan (St Paul's Hospital, Vancouver, BC, Canada); Grant Fisher (London Health Sciences Centre, London, ON, Canada); Tara Miller (Duke University Hospital, Durham, NC USA); Maureen Flattery (Virginia Commonwealth University Health System, Richmond, VA, USA); Kristin Ludrosky (Cleveland Clinic, OH, USA); Bernice Coleman (Cedars-Sinai Medical Center, Los Angeles, CA, USA); Jacqueline Trammell (Kaiser Permanente Santa Clara Medical Center, Santa Clara, CA, USA); Katherine St. Clair Andrew Kao (St. Luke's Hospital, Kansas City, MO, USA); Maria Molina (Hospital of the University of Pennsylvania, Philadelphia, PA, USA); Karyn Ryan Canales (Ochsner Medical Center, New Orleans, LA, USA); Samira Scalso de Almeida (Hospital Israelita Albert Einstein, São Paulo, Brazil); Andrea Cotait Ayoub (Instituto Dante Pazzanese de Cardiologia, São Paulo, Brazil); Fernanda Barone (Instituto do Coração da Universidade de São Paulo, São Paulo Brazil); Michelle Harkess (St. Vincent's Hospital, Sydney, Australia); Joanne Maddicks-Law (The Prince Charles Hospital, Brisbane, Australia)]. 
Keywords:

Heart transplantation Chronic illness management

Multidisciplinary teams with a multidisciplinary team may offer higher levels of CIM, a care model that has the potential to improve outcomes after HTx.

Methods: We conducted a secondary analysis of the BRIGHT study, a cross-sectional study in 11 countries. Multidisciplinarity in the 36 HTx centers was assessed through HTx director reports and was defined as having a team that was composed of physician(s), nurse(s), and another healthcare professional (either a social worker, psychiatrist, psychologist, pharmacist, dietician, physical therapist, or occupational therapist). CIM was assessed with the Patient Assessment of Chronic Illness Care (PACIC). Multiple linear regression assessed the relationship between multidisciplinarity and the level of CIM.

Results: Twenty-nine (80.6\%) of the HTx centers had a multidisciplinary team. Furthermore, multidisciplinarity was significantly associated with higher levels of CIM $(\beta=5.2, P=0.042)$.

Conclusion: Majority of the HTx centers follows the ISHLT recommendation for a multidisciplinary approach. Multidisciplinarity was associated with CIM and point toward a structural factor that needs to be in place for moving toward CIM.

\section{Introduction}

Heart transplantation (HTx) is an established treatment for patients with end-stage heart failure; more than 4000 HTx are performed annually. ${ }^{1}$ Although advanced surgical techniques, better immunosuppressive therapies and improved infection control measures have dramatically improved short-term outcomes in organ transplantation, long-term survival rates have remained disappointingly stable during the past two decades. ${ }^{2}$ HTx recipients are regarded as chronically ill as they need life-long medical supervision for their transplanted organ as well as for new or existing co-morbidities like hypertension, diabetes mellitus, obesity, chronic kidney disease, or cancer. ${ }^{3-5}$ Moreover, they have to engage in a healthy lifestyle and adherence to their treatment plan to prevent complications like acute rejection and reduce onset and progression of co-morbidities. ${ }^{5-7}$ The plateau in long-term survival rate might be explained by deficits in follow-up care (e.g. lack of continuity of care) and sub-optimal support for selfmanagement that aims to increase patients' ability and motivation to optimally integrate and follow a complex therapeutic regimen in their daily lives. ${ }^{5}$

Chronic illness management (CIM), a care model which emphasizes continuity of care and promotes self-management support for patients, could therefore provide an opportunity to improve long-term outcomes post HTx given promising results in other chronic patient populations. ${ }^{5,8,9}$ Studies in non- HTx populations have shown that CIM is associated with decreased healthcare utilization, ${ }^{10,11}$ improvements in health-related behaviors, ${ }^{12}$ increased quality-of-life, ${ }^{11}$ and greater patient and caregiver satisfaction. ${ }^{12}$ In transplantation, the reengineering of transplant follow-up care according to the principles of CIM has resulted in improved clinical outcomes, reduced health care utilization, and reduced costs. ${ }^{10,13}$

In the most recent guidelines for the care of HTx recipients, the International Society of Heart and Lung Transplantation (ISHLT) recommended that transplant centers utilize a multidisciplinary approach to patient management. ${ }^{6}$ This recommendation is similar to the Centers for Medicare and Medicaid policy that specifies that a multidisciplinary team should be involved in the care of transplant recipients throughout all phases of the transplantation. ${ }^{14}$ Similarly, Brazil has a law that requires a multidisciplinary approach in the care of transplant patients (Samira de Almeida, Senior Transplant Nurse, email communication, February 9, 2017). A multidisciplinary approach entails the collaboration of healthcare professionals from a range of disciplines to deliver comprehensive care that addresses the HTx recipient's medical, behavioral, and psychosocial needs. ${ }^{15}$ In addition to physicians and nurses, the ISHLT recommends the integration of pharmacists, dieticians, social workers, physiotherapists, and psychiatry specialists to the HTx recipient management team. ${ }^{6}$ A multidisciplinary team can address the multiple medical, psychosocial, and behavioral care needs of HTx recipients and is a prerequisite for successful CIM.

Despite the evidence supporting the benefit of a multidisciplinary approach in CIM, very little is known regarding the actual proportion of HTx centers that meet the ISHLT recommendation for a multidisciplinary team approach. Subsequently, the association of multidisciplinarity with the level of CIM that HTx recipients receive is currently not known. Hence, the objectives of this study were to: 1) explore the proportion of HTx centers that have a multidisciplinary team and describe team composition and 2) assess the relationship between multidisciplinarity and the level of CIM in HTx centers.

\section{Methods}

This is a secondary data analysis of the multi-center, crosssectional Building Research Initiative Group: Chronic Illness Management and Adherence in Transplantation (BRIGHT) study. Detailed information on the methodology of the BRIGHT study has been previously published. ${ }^{16}$ The primary aim of the BRIGHT study was to examine the practice patterns and the prevalence and variability of non-adherence to prescribed treatment regimen in 36 HTx centers in 11 countries across 4 continents.

\section{Sample and setting}

The BRIGHT study used a multi-staged sampling approach. A convenience sample of 36 heart transplant centers in Europe (Belgium, France, Spain, Italy, the UK, Switzerland and Germany), North America (USA, Canada), South America (Brazil) and Australia was recruited. The heart transplant director of each of the 36 centers was included. Within each center, HTx recipients were also recruited using proportionate random sampling. Data were collected between March 2012 and October 2015. For this secondary analysis, data from the 1397 HTx recipients and the 36 HTx center directors were used.

The inclusion criteria were: (1) HTx recipient, (2) $\geq 18$ years of age at time of inclusion, (3) transplanted and followed up in the participating transplant center, (4) first HTx, (5) single organ Tx, (6) 1-5 years post-HTx at time of inclusion, (7) independent management of medication taking without professional support, (8) able to read, understand, and (9) sign a written informed consent. Patients were excluded if they participated in adherenceintervention studies or drug trials during the past 6 months or if they were receiving professional support in taking their medications. ${ }^{16}$ 
Variables and measurement

Information on HTx centers and HTx recipients

Data on center characteristics were collected with an investigator-developed, self-report instrument completed by the HTx center's director. ${ }^{16}$ Information from each center included the country and area (urban/suburban/rural area), the type of center (university teaching hospital/other), and size (based on the number of HTx performed the last 5 years; wherein, centers that performed 50-74 HTx were classified as small, 75-100 as medium, and $>100$ as large based on the ISHLT criteria). ${ }^{16}$ Data on patient characteristics were collected through self-report instruments and included age in years, gender, and number of years post-transplant.

\section{Multidisciplinarity and composition of the follow-up team}

Based on the ISHLT recommendation, ${ }^{6}$ multidisciplinarity was defined as having a team that was composed of physician(s), nurse(s), and at least one other healthcare professional (either a social worker, psychiatrist, psychologist, pharmacist, dietitian, physical therapist, or occupational therapist), who is/are routinely involved with outpatient follow-up care. The position of transplant coordinator, who is the person who arranges the transplant process, coordinates team meetings, and works in pre- or posttransplant care and/or procurement, can be assumed by different healthcare professionals (e.g. nurse, physician, etc.). Data on posttransplant follow-up team composition and presence of a transplant coordinator were collected using a self-administered survey that was completed by the HTx center's transplant director.

\section{Level of chronic illness management}

Level of CIM was assessed from the patient perspective using the short version of the Patient Assessment of Chronic Illness Care (PACIC) instrument, ${ }^{17,18}$ which was part of the BRIGHT patient's self-report questionnaire. ${ }^{16}$ The PACIC was developed to measure the extent to which patients receive care according to the principles of the Chronic Care Model. ${ }^{17,18}$ It assesses patient activation, goal setting, problem solving, contextual counseling, delivery system design, decision support, and follow-up/coordination. ${ }^{17,18}$ The short version consists of 11 items, scored on a 5-point Likert scale from "almost never" to "almost always", with an overall summary score ranging from 11 to $55 .{ }^{18,19}$ Higher scores indicate a higher level of CIM. The instrument showed high internal consistency (Cronbach's $\alpha 0.95-0.96){ }^{17,18}$

\section{Ethical considerations}

Every participating transplant center in the BRIGHT study obtained ethical approval from their institutional review board and/or national ethics committee. Written informed consents were obtained from the HTx recipients. To maintain confidentiality, completed questionnaires were placed in the provided envelopes and sealed before being returned to the data collector.

\section{Statistical analyses}

Center and patient characteristics and the compositions of the HTx center's outpatient, follow-up care teams were analyzed descriptively. Fisher's Exact Test was used to assess for variability in the multidisciplinarity of HTx centers across the 11 countries and for variability in the types of health professions included in the multidisciplinary teams. Finally, the level of CIM (PACIC score) was averaged by HTx center, and multiple linear regression was used to assess the relationship between multidisciplinarity and level of CIM adjusting for center size, location, and center type. Level of significance was set at 0.05. Data were analyzed using Stata14.

\section{Results}

Characteristics of the 36 HTx centers and 1397 HTx recipients are presented in Table 1 . The majority of the centers $(n=19 ; 52.8 \%)$ were located in Europe, followed by North America $(n=12 ; 33.3 \%)$, then South America ( 3 in Brazil), and Australia (2). The majority ( $n=23 ; 63.9 \%$ ) were classified as large centers (i.e. $>100$ HTx performed/5 years). Thirty-two centers (88.9\%) were located in urban areas and thirty (83.3\%) were university teaching hospitals. The overall mean PACIC score was $38.3 \pm 10.9$ (range: $25.5-47.6$ ).

Twenty-nine (80.6\%) of the 36 HTx centers had a multidisciplinary team. There was no significant variability in terms of the proportion of HTx centers that had a multidisciplinary team across the 11 countries $(P=0.973)$ (Table 2$)$. Similarly, there was no significant difference between countries that have policies mandating the use of the multidisciplinary approach in the followup care of transplant recipients (Table 3 ) and countries without such policies $(81.8 \%$ vs. $80 \%, P=1.00)$.

There was non-significant variability in the types of professionals represented in the multidisciplinary teams across study sites (Table 2). There was no significant difference in the proportion of HTx centers across the 11 countries that included surgeons $(P=0.554)$, cardiologists $(P=0.278)$, hospitalists $(P=0.150)$, transplant fellows $(P=0.451)$, advanced practice nurse (APNs) $(P=0.533)$, transplant nurses $(P=0.086)$, cardiac rehabilitation nurses $(P=0.834)$, other types of registered nurse $(P=0.572)$, LPNs $(P=0.291)$, psychiatrists $(P=0.086)$, psychologists $(P=0.296)$, social workers $(P=0.352)$, pharmacists $(P=0.376)$, dieticians $(P=0.309)$, physical therapists $(P=0.089)$, and occupational therapists $(P=0.238)$ in their multidisciplinary teams (Table 2$)$.

The majority (44.4\%) of the HTx centers had a cardiologist as the director of their heart transplant program, while fourteen (38.9\%) centers had a surgeon as their transplant director. All 36 of the HTx centers had physicians in their outpatient follow-up team. Thirtyfive $(97.2 \%)$ of the HTx centers had nurses as part of their followup team. Finally, thirty $(83.3 \%)$ of the HTx centers included at least one type of clinician from another profession recommended by the ISHLT (i.e. social work, psychiatry, psychology, pharmacy, dietetics, physical therapy, occupational therapy). Among the other healthcare professions, psychiatry and occupational therapy were the most under-represented, wherein only two (5.6\%) of the HTx centers had psychiatrists or occupational therapists as part of their follow-up teams. On the other hand, seventeen (47.2\%) of the HTx centers had social workers as part of their follow-up teams.

\section{Transplant coordinator}

All of the HTx centers had a transplant coordinator; however, only twenty (55.6\%) had a transplant coordinator as part of their outpatient, follow-up teams. Sixteen (45.7\%) of the centers had a registered nurse as their transplant coordinator, fifteen $(42.9 \%)$ had an APN, and 4 (11.4\%) had another type of healthcare professional as their transplant coordinator.

\section{Multidisciplinarity and level of CIM}

The mean PACIC score for the centers with multidisciplinary teams was $38.4 \pm 4.2$ while for the non-multidisciplinary centers it was $35.6 \pm 6.2$. Having a multidisciplinary team was significantly associated with higher levels of CIM as perceived by the HTx recipients $(\beta=5.2,95 \% \mathrm{CI} 0.19-10.2, P=0.042)$ even after controlling for center size, location, and center type. 


\section{Discussion}

This is the largest study to date and the first to examine the composition and role of HTx follow-up teams from countries outside North America. The majority of the HTx centers included in this study met the ISHLT recommendation of having a multidisciplinary team involved in the follow-up care of HTx recipients. Our study showed that multidisciplinarity was significantly associated with higher level of CIM. Indeed CIM requires that a team, which is composed of a variety of health professionals with medical, psychosocial and behavioral competencies, address the diverse needs of the HTx population. For instance, psychosocial problems like depression $^{20,21}$ and unemployment ${ }^{22,23}$ are common in the HTx population, as well as behavioral issues such as non-adherence to different aspects of the therapeutic regimen. ${ }^{24}$ Nurses, psychiatrists, psychologists, and social workers have the necessary training and knowledge to address these psychosocial needs; hence, having them in the team would logically result in higher level of CIM yet it is finally the model of care implemented and the intervention applied by the various involved disciplines that will determine optimal interplay of professionals to achieve favorable posttransplant outcomes. The positive association between multidisciplinarity and level of CIM that we found is consistent with previous research in other chronic illness populations. Harris et $\mathrm{al}^{25}$ reported that chronically ill patients, who received outpatient care from a multidisciplinary team, rated the level of CIM that they received higher compared to patients who did not receive multidisciplinary care. Admittedly, as with our current study, these studies did not report on what types of intervention the health professionals used and how they collaborated to achieve optimal outcomes. Indeed, it should be noted that having a multidisciplinary team does not automatically guarantee effective interdisciplinary collaboration or effective used of available state of art evidence in view of medical, behavioral or psychosocial interventions. While having a cadre of professionals, each contributing their own specialized skills and knowledge, could improve CIM; the inherent differences among professions could also potentially impede true collaboration. It is well documented in the field of health sociology, that healthcare professionals' need to maintain professional identities hinders interdisciplinary collaboration. ${ }^{26}$ Hartgerink et $\mathrm{al}^{27}$ found that physicians were less open to interdisciplinary collaboration compared to nurses. Even within the medical profession, doctors have been found to share more information with colleagues from the same discipline. ${ }^{26}$ Given the potential of the multidisciplinary approach to significantly improve CIM and, ultimately, health outcomes, concerted effort should be taken to foster interdisciplinary collaboration.

There was no significant variability in terms of multidisciplinarity in HTx centers, even between countries with policies that mandate the presence of a multidisciplinary team in the follow-up care of transplant recipients and countries without such policies, which suggests that having a multidisciplinary team is achievable regardless of the healthcare system or payment model in place. Similarly, there was no significant variability in the types of health professionals represented in the multidisciplinary teams across. The non-significant findings could be due to the lack of statistical power as a result of our study's relatively small sample size. Further studies are needed to explore whether team composition impacts CIM and HTx outcomes, in order to determine the optimal multidisciplinary team composition.

While it can be argued that multidisciplinarity is a prerequisite of CIM, it does not, however, guarantee CIM, as CIM requires a 'reengineering' of transplant follow-up care aligned with the principles of CIM (i.e. continuity and coordination of care between settings; collaboration between patients, families, and communities; patient self-management and decision-making support; and preventative measures ${ }^{28}$ ). In their landmark study, Bissonette et $\mathrm{al}^{10}$ reengineered their kidney transplant program according to the principles of CIM. The intervention consisted of strategies for disease self-management, guidelines-driven care, adherenceenhancing interventions, shared decision-making, and health care delivery and system reorganization as well as the introduction of an APN. Their findings showed that adherence to guidelines improved and, more importantly, that emergency room visits and hospital admissions decreased in the intervention group. ${ }^{10}$ Similarly, a randomized controlled trial that examined the impact of a telemedicine-supported chronic care case management intervention showed that renal transplant recipients in the intervention group had significantly fewer unplanned admissions and shorter

Table 1

Center and patient characteristics and average level of chronic illness management (PACIC).

\begin{tabular}{|c|c|c|c|c|c|c|c|c|c|c|c|c|}
\hline \multirow[t]{2}{*}{ Centers, $n(\%)$} & \multirow{2}{*}{$\begin{array}{l}\text { Overall } \\
N=36\end{array}$} & \multicolumn{7}{|l|}{ Europe } & \multicolumn{2}{|l|}{ N. America } & \multirow{2}{*}{$\begin{array}{l}\text { S. America } \\
\text { Brazil } \\
n=3\end{array}$} & \multirow{2}{*}{$\begin{array}{l}\text { Australia } \\
\text { Australia } \\
n=2\end{array}$} \\
\hline & & $\begin{array}{l}\text { Belgium } \\
n=2\end{array}$ & $\begin{array}{l}\text { France } \\
n=3\end{array}$ & $\begin{array}{l}\text { Germany } \\
n=2\end{array}$ & $\begin{array}{l}\text { Italy } \\
n=2\end{array}$ & $\begin{array}{l}\text { Spain } \\
n=5\end{array}$ & $\begin{array}{l}\text { Switzerland } \\
n=2\end{array}$ & $\begin{array}{l}\text { UK } \\
n=3\end{array}$ & $\begin{array}{l}\text { Canada } \\
n=4\end{array}$ & $\begin{array}{l}\text { USA } \\
n=8\end{array}$ & & \\
\hline \multicolumn{13}{|l|}{ Size $^{a}$} \\
\hline Large & $23(63.9)$ & $1(50)$ & $3(100)$ & $1(50)$ & $2(100)$ & $4(80)$ & 0 & $2(66.7)$ & $2(50)$ & $6(75)$ & $1(33.3)$ & $1(50)$ \\
\hline Medium & $8(22.2)$ & $1(50)$ & 0 & $1(50)$ & 0 & $1(20)$ & 0 & $1(33.3)$ & $1(25)$ & $2(25)$ & $1(33.3)$ & 0 \\
\hline Small & $5(13.9)$ & 0 & 0 & 0 & 0 & 0 & $2(100)$ & 0 & $1(25)$ & 0 & $1(33.3)$ & $1(50)$ \\
\hline \multicolumn{13}{|l|}{ Location } \\
\hline Urban & $32(88.9)$ & $1(50)$ & $3(100)$ & $2(100)$ & $2(100)$ & $5(100)$ & $2(100)$ & $1(33.3)$ & $4(100)$ & $7(87.5)$ & $3(100)$ & $2(100)$ \\
\hline $\begin{array}{l}\text { Suburban/ } \\
\text { Other }\end{array}$ & $4(11.1)$ & $1(50)$ & 0 & 0 & 0 & 0 & 0 & $2(66.7)$ & 0 & $1(12.5)$ & 0 & 0 \\
\hline \multicolumn{13}{|l|}{ Center type } \\
\hline $\begin{array}{l}\text { University } \\
\text { teaching }\end{array}$ & $30(83.3)$ & $2(100)$ & $3(100)$ & $2(100)$ & $2(100)$ & $5(100)$ & $2(100)$ & $3(100)$ & $4(100)$ & $5(62.5)$ & 0 & $2(100)$ \\
\hline Other & $6(16.7)$ & 0 & 0 & 0 & 0 & 0 & 0 & 0 & 0 & $3(37.5)$ & $3(100)$ & 0 \\
\hline Patients & $\begin{array}{l}\text { Overall } \\
N=1397\end{array}$ & $\begin{array}{l}\text { Belgium } \\
n=74\end{array}$ & $\begin{array}{l}\text { France } \\
n=160\end{array}$ & $\begin{array}{l}\text { Germany } \\
n=67\end{array}$ & $\begin{array}{l}\text { Italy } \\
n=111\end{array}$ & $\begin{array}{l}\text { Spain } \\
n=227\end{array}$ & $\begin{array}{l}\text { Switzerland } \\
n=47\end{array}$ & $\begin{array}{l}\text { UK } \\
n=99\end{array}$ & $\begin{array}{l}\text { Canada } \\
n=121\end{array}$ & $\begin{array}{l}\text { USA } \\
n=340\end{array}$ & $\begin{array}{l}\text { Brazil } \\
n=101\end{array}$ & $\begin{array}{l}\text { Australia } \\
n=51\end{array}$ \\
\hline Age $^{\mathrm{b}}$, years & $53.5 \pm 13.3$ & $54.1 \pm 12.6$ & $50.5 \pm 13$ & $55.7 \pm 10.4$ & $57.2 \pm 12.5$ & $57 \pm 11.7$ & $49.2 \pm 14.6$ & $48.8 \pm 14.7$ & $54.6 \pm 13.4$ & $55.5 \pm 12.7$ & $45.3 \pm 13.2$ & $49 \pm 14.3$ \\
\hline Gender, \% male & 72.7 & 67.6 & 75.6 & 76.9 & 83.8 & 76.7 & 68.1 & 77.6 & 72.5 & 68 & 68 & 60.8 \\
\hline Years post $\mathrm{HTx}^{\mathrm{b}}$ & $3.4 \pm 1.4$ & $3.4 \pm 1.2$ & $3.7 \pm 1.4$ & $3.4 \pm 1.4$ & $3.2 \pm 1.3$ & $3.6 \pm 1.4$ & $3.5 \pm 1.2$ & $3.5 \pm 1.2$ & $3.7 \pm 1.5$ & $3 \pm 1.3$ & $2.8 \pm 1.5$ & $4.2 \pm 1.5$ \\
\hline $\begin{array}{l}\text { PACIC }^{\mathrm{b}} \\
\quad(n=1282)\end{array}$ & $38.3 \pm 10.9$ & $36.8 \pm 11$ & $34.6 \pm 11$ & $38.4 \pm 10.1$ & $41.6 \pm 7.1$ & $40.2 \pm 9.8$ & $38.3 \pm 10.9$ & $32.4 \pm 12.1$ & $35.1 \pm 11.5$ & $41.8 \pm 9.9$ & $37.3 \pm 10.9$ & $34.1 \pm 12.2$ \\
\hline
\end{tabular}

${ }^{a}$ According to the categories from ISHLT (small: 50-74 HTx/5 years; medium: 75-100/5 years; large: >100 HTx/5 years).

b Mean \pm SD. 
Table 2

Proportion of HTx centers with multidisciplinary teams and professions involved in routine follow-up care.

\begin{tabular}{|c|c|c|c|c|c|c|c|c|c|c|c|c|}
\hline & \multirow{2}{*}{$\begin{array}{l}\text { Overall } \\
N=36\end{array}$} & \multicolumn{7}{|l|}{ Europe } & \multicolumn{2}{|c|}{ N. America } & \multirow{2}{*}{$\begin{array}{l}\text { S. America } \\
\text { Brazil } \\
N=3\end{array}$} & \multirow{2}{*}{$\begin{array}{l}\text { Australia } \\
\text { Australia } \\
N=2\end{array}$} \\
\hline & & $\begin{array}{l}\text { Belgium } \\
N=2\end{array}$ & $\begin{array}{l}\text { France } \\
N=3\end{array}$ & $\begin{array}{l}\text { Germany } \\
N=2\end{array}$ & $\begin{array}{l}\text { Italy } \\
N=2\end{array}$ & $\begin{array}{l}\text { Spain } \\
N=5\end{array}$ & $\begin{array}{l}\text { Switzerland } \\
N=2\end{array}$ & $\begin{array}{l}\mathrm{UK} \\
N=3\end{array}$ & $\begin{array}{l}\text { Canada } \\
N=4\end{array}$ & $\begin{array}{l}\text { USA } \\
N=8\end{array}$ & & \\
\hline $\begin{array}{l}\text { Centers with multidisciplinary } \\
\text { teams }^{\text {a }}\end{array}$ & $29(80.6)$ & $2(100)$ & $2(66.7)$ & $2(100)$ & $2(100)$ & $3(60)$ & $2(100)$ & $2(66.7)$ & $3(75)$ & $7(87.5)$ & $2(66.7)$ & $2(100)$ \\
\hline \multicolumn{13}{|l|}{ Profession, $n(\%)$} \\
\hline Physicians & $36(100)$ & $2(100)$ & $3(100)$ & $2(100)$ & $2(100)$ & $5(100)$ & $2(100)$ & $3(100)$ & $4(100)$ & $8(100)$ & $3(100)$ & $2(100)$ \\
\hline Surgeons & $5(13.9)$ & $1(50)$ & 0 & 0 & $1(50)$ & 0 & 0 & $1(33.3)$ & $1(25)$ & $1(12.5)$ & 0 & 0 \\
\hline Cardiologist & $35(97.2)$ & $2(100)$ & $3(100)$ & $2(100)$ & $1(50)$ & $5(100)$ & $2(100)$ & $3(100)$ & $4(100)$ & $8(100)$ & $3(100)$ & $2(100)$ \\
\hline Hospitalist/Intensivist & $3(8.3)$ & $1(50)$ & 0 & $1(50)$ & 0 & 0 & 0 & 0 & $1(25)$ & 0 & 0 & 0 \\
\hline Tx fellow & $16(44.4)$ & 0 & 0 & $1(50)$ & $1(50)$ & $2(40)$ & $1(50)$ & $3(100)$ & $2(50)$ & $3(37.5)$ & $1(33.3)$ & $2(100)$ \\
\hline Nurses & $35(97.2)$ & $2(100)$ & $3(100)$ & $2(100)$ & $2(100)$ & $5(100)$ & $2(100)$ & $3(100)$ & $4(100)$ & $7(87.5)$ & $3(100)$ & $2(100)$ \\
\hline $\mathrm{APN}^{\mathrm{b}}$ & $15(41.7)$ & $2(100)$ & 0 & $1(50)$ & $1(50)$ & $2(40)$ & 0 & $2(66.7)$ & $2(50)$ & $4(50)$ & 0 & $1(50)$ \\
\hline TNS $^{\mathrm{C}}$ & $18(50)$ & $1(50)$ & $3(100)$ & $1(50)$ & $2(100)$ & 0 & 0 & $2(66.7)$ & $2(50)$ & $2(25)$ & $3(100)$ & $2(100)$ \\
\hline Cardiac Rehab Nurse & $5(13.9)$ & 0 & 0 & 0 & 0 & $1(20)$ & 0 & $1(33.3)$ & $2(50)$ & $1(12.5)$ & 0 & 0 \\
\hline Other RN & $17(47.2)$ & $1(50)$ & 0 & $2(100)$ & 0 & $3(60)$ & $2(100)$ & $1(33.3)$ & $2(50)$ & $4(50)$ & $1(33.3)$ & $1(50)$ \\
\hline LPN & $8(22.2)$ & 0 & 0 & $2(100)$ & 0 & $2(40)$ & $1(50)$ & $1(33.3)$ & $1(25)$ & $1(12.5)$ & 0 & 0 \\
\hline Other & $30(83.3)$ & $2(100)$ & $2(66.7)$ & $2(100)$ & $2(100)$ & $3(60)$ & $2(100)$ & $2(66.7)$ & $3(75)$ & $8(100)$ & $2(66.7)$ & $2(100)$ \\
\hline Psychiatrist & $2(5.6)$ & 0 & 0 & $1(50)$ & 0 & 0 & $1(50)$ & 0 & 0 & 0 & 0 & 0 \\
\hline Psychologist & $11(30.6)$ & $1(50)$ & 0 & $1(50)$ & $2(100)$ & $1(20)$ & $1(50)$ & $1(33.3)$ & 0 & $2(25)$ & $2(66.7)$ & 0 \\
\hline Social worker & $17(47.2)$ & $1(50)$ & $1(33.3)$ & $1(50)$ & 0 & $1(20)$ & $2(100)$ & 0 & $2(50)$ & $5(62.5)$ & $2(66.7)$ & $2(100)$ \\
\hline Pharmacist & $16(44.4)$ & $1(50)$ & $1(33.3)$ & $2(100)$ & 0 & $2(40)$ & $1(50)$ & 0 & $2(50)$ & $6(75)$ & $1(33.3)$ & 0 \\
\hline Dietician & $8(22.2)$ & $1(50)$ & 0 & 0 & 0 & 0 & 0 & $1(33.3)$ & $1(25)$ & $2(25)$ & $1(33.3)$ & $2(100)$ \\
\hline Physical therapist & $10(27.8)$ & $1(50)$ & 0 & $1(50)$ & 0 & 0 & 0 & $2(66.7)$ & $2(50)$ & $1(12.5)$ & $1(33.3)$ & $2(100)$ \\
\hline Occupational therapist & $2(5.6)$ & 0 & 0 & 0 & 0 & 0 & 0 & $1(33.3)$ & 0 & 0 & 0 & $1(50)$ \\
\hline
\end{tabular}

a Physician, Nurse, \& Social Worker/Psychiatrist/Psychologist/Pharmacist/Dietician/Physical Therapist/Occupational Therapist.

b Advanced Practice Nurse.

c Transplant Nurse Specialist (without master's degree).

length of unplanned hospital stay compared to those in the standard care group. ${ }^{13}$

This study has several limitations. First, given that this was a secondary analysis of existing data, it is unclear whether the presence of other factors not assessed in this study confounded the significant association between multidisciplinarity and level of CIM. Second, the cross-sectional design precludes causal inferences. Third, the convenience sample of HTx centers may have caused selection bias toward centers with more favorable care models given the prime questions of the BRIGHT study, although the randomized patient-selection strengthens our findings. In addition, despite being the largest study of its kind, the sample size (36 HTx centers) was relatively small, which could limit the generalizability of our findings. Finally, information on the presence/absence of an infectious disease specialist, which was one of the professions recommended by the ISHLT, ${ }^{6}$ was not collected.

Future research should assess, not just the presence of a multidisciplinary team, but also if actual interdisciplinary collaboration exists, the interventions used by the different health

Table 3

Countries with policies mandating the use of a multidisciplinary team in the followup care of transplant recipients.

\begin{tabular}{ll}
\hline With policy & Without policy \\
\hline Brazil $^{\mathrm{a}}$, USA $^{\mathrm{b}}$ & $\begin{array}{l}\text { Belgium }^{\mathrm{c}}, \text { France }^{\mathrm{c}}, \text { Spain }^{\mathrm{d}}, \text { Italy }^{\mathrm{e}}, \text { United Kingdom }^{\mathrm{f}}, \\
\text { Switzerland }^{\mathrm{c}}, \text { Canada }^{\mathrm{g}}, \text { Australia }^{\mathrm{h}}\end{array}$ \\
\hline
\end{tabular}

\footnotetext{
a Samira de Almeida, Senior Transplant Nurse, email communication, February 9, 2017.

b Department of Health and Human Services. Hospital conditions of participation: requirements for approval and re-approval of transplant centers to perform organ transplants. Fed Regist. 2007; 72 (61):15198-15280.

c Sabina De Geest,PhD, RN, email communication, February 16, 2017.

d Marisa Crespo, MD, email communication, February 11, 2017.

e Paolo De Simone, MD, email communication, February 9, 2017.

${ }^{f}$ Department of Health. Organs for transplant: a report from the organ donation taskforce.http://www.nhsbt.nhs.uk/to2020/resources/OrgansfortransplantsTheOrgan DonorTaskForce1streport.pdf.

g Annemarie Kaan, CNS Heart Failure, VAD, Transplant, email communication, February 9, 2017.

h Peter Macdonald, MD, email communication, February 9, 2017.
}

professionals and how this impacts CIM and relevant health outcomes in HTx recipients. Furthermore, studies should assess how different clinicians contribute to successful CIM in HTx. Finally, as team compositions and their interventions are only one aspect of CIM models, ${ }^{28}$ studies should also identify other predictors associated with CIM in HTx follow-up (e.g. community and organization resources and policies, clinical information systems). The evaluation of the impact of systems of care based on multidisciplinarity and CIM is a priority as this is a promising pathway for improving long-term outcomes after transplantation.

\section{Conclusion}

In conclusion, this study showed that while the composition of the follow-up teams in HTx centers varied, majority of the HTx centers met the ISHLT recommendation of having a multidisciplinary team and this was associated with higher levels of CIM. Future research should build upon the findings of this study and explore the composition, duration and impact of CIM interventions delivered by multidisciplinary follow-up teams in HTx.

\section{References}

1. Lund LH, Edwards LB, Ms YK, et al. The Registry of the International Society for Heart and Lung Transplantation: 32nd official adult heart transplantation report - 2015. J Heart Lung Transpl. 2015;34(10). http://dx.doi.org/10.1016/ j.healun.2015.08.003. online document.

2. Lodhi SA, Lamb KE, Meier-Kriesche HU. Solid organ allograft survival improvement in the United States: the long-term does not mirror the dramatic short-term success. Am J Transpl. 2011;11(6):1226-1235. http://dx.doi.org 10.1111/j.1600-6143.2011.03539.x.

3. Chong VH, Singh J, Parry H, et al. Management of noncardiac comorbidities in chronic heart failure. Cardiovasc Ther. 2015;33(5):300-315. http://dx.doi.org/ 10.1111/1755-5922.12141.

4. Jaramillo N, Segovia J, Gómez-Bueno M, et al. Characteristics of patients with survival longer than 20 years following heart transplantation. Rev Española Cardiol (English Ed). 2013;66(10):797-802. http://dx.doi.org/10.1016 j.rec.2013.05.016.

5. De Geest S, Dobbels F, Gordon E, De Simone P. Chronic illness management as an innovative pathway for enhancing long-term survival in transplantation. Am J Transpl. 2011;11:2262-2263. http://dx.doi.org/10.1111/j.16006143.2011.03714.x 
6. Costanzo MR, Dipchand A, Starling R, et al. The International Society of Heart and Lung Transplantation guidelines for the care of heart transplant recipients. $J$ Heart Lung Transpl. 2010;29(8):914-956. http://dx.doi.org/10.1016/ j.healun.2010.05.034.

7. Kansara P, Kobashigawa JA. Management of heart transplant recipients: reference for primary care physicians. Postgrad Med. 2012;124(4):215-224. http://dx.doi.org/10.3810/pgm.2012.07.2563.

8. Busse R, Blumel M, Scheller-Kreinsen D, Zentner A. Tackling Chronic Disease in Europe: Strategies, Interventions and Challenges. 1st ed. Copenhagen, Denmark: World Health Organization, on behalf of the European Observatory on Health Systems and Policies; 2010.

9. Nuno R, Coleman K, Bengoa R, Sauto R. Integrated care for chronic conditions: the contribution of the ICCC framework. Health Policy (New York). 2012;105(1): 55-64. http://dx.doi.org/10.1016/j.healthpol.2011.10.006.

10. Bissonnette J, Woodend K, Davies B, Stacey D, Knoll GA. Evaluation of a collaborative chronic care approach to improve outcomes in kidney transplant recipients. Clin Transpl. 2013;27(2):232-238. http://dx.doi.org/10.1111/ ctr.12068.

11. Drewes HW, Steuten LMG, Lemmens LC, et al. The effectiveness of chronic care management for heart failure: meta-regression analyses to explain the heterogeneity in outcomes. Health Serv Res. 2012;47(5):1926-1959. http:// dx.doi.org/10.1111/j.1475-6773.2012.01396.x.

12. de Bruin SR, Versnel N, Lemmens LC, et al. Comprehensive care programs for patients with multiple chronic conditions: a systematic literature review. Health Policy (New York). 2012;107(2-3):108-145. http://dx.doi.org/10.1016/ j.healthpol.2012.06.006.

13. Schmid A, Hils S, Bogatyreva L, Hauschke D, De Geest S, Pisarski P. Telemedically-supported case management of living-donor renal transplant recipients to optimize routine evidence-based aftercare: a single-center randomized controlled trial. Am J Transpl; 2016:1-36.

14. Department of Health and Human Services. Hospital conditions of participation: requirements for approval and re-approval of transplant centers to perform organ transplants. Fed Regist. 2007;72(61):15198-15280. http:// dx.doi.org/10.1097/DMP.0b013e3180cac8c7.

15. Mitchell GK, Tieman JJ, Shelby-James TM. Multidisciplinary care planning and teamwork in primary care. Med J Aust. 2008;188:S61-S64.

16. Berben L, Denhaerynck K, Dobbels F, et al. Building research initiative group: chronic illness management and adherence in transplantation (BRIGHT) study: study protocol. J Adv Nurs. 2015;71(3):642-654. http://dx.doi.org/10.1111/jan.12519.
17. Gugiu P, Coryn C, Clark R, Kuehn A. Development and evaluation of the short version of the patient assessment of chronic illness care instrument. Chronic Illn. 2009;5(4):268-276. http://dx.doi.org/10.1177/1742395309348072.

18. Iglesias K, Burnand B, Peytremann-Bridevaux I. PACIC Instrument: disentangling dimensions using published validation models. Int J Qual Heal Care. 2014;26(3):250-260. http://dx.doi.org/10.1093/intqhc/mzu042.

19. Jackson GL, Weinberger M, Hamilton NS, Edelman D. Racial/ethnic and educational-level differences in diabetes care experiences in primary care. Prim Care Diabetes. 2008;2(1):39-44. http://dx.doi.org/10.1016/j.pcd.2007.11.002.

20. Dew MA, DiMartini AF. Psychological disorders and distress after adult cardiothoracic transplantation. I Cardiovasc Nurs(5 Suppl):S51-S66, http:// graphics.tx.ovid.com/ovftpdfs/FPDDNCIBADKAFH00/fs047/ovft/live/gv024/ 00005082/00005082-200509001-00007.pdf, 2005;20.

21. Dobbels F, De Geest S, Martin S, Van Cleemput J, Droogne W, Vanhaecke J. Prevalence and correlates of depression symptoms at 10 years after heart transplantation: continuous attention required. Transpl Int. 2004;17(8):424431. http://dx.doi.org/10.1111/j.1432-2277.2004.tb00465.x.

22. Kristen A, Ammon K, Koch A, et al. Return to work after heart transplantation: discrepancy with subjective work ability. Transplantation. 2009;87(7):10011005. http://dx.doi.org/10.1097/TP.0b013e31819ca1ee.

23. White-Williams C, Jalowiec A, Grady K. Who returns to work after heart transplantation? J Heart Lung Transpl. 2005;24(12):2255-2261.

24. Dew MA, DiMartini AF, De Vito Dabbs A, et al. Rates and risk factors for nonadherence to the medical regimen after adult solid organ transplantation. Transplantation. 2007;83(7):858-873. http://dx.doi.org/10.1097/ 01.tp.0000258599.65257.a6.

25. Harris MF, Jayasinghe UW, Taggart JR, et al. Multidisciplinary team care arrangements in the management of patients with chronic disease in Australian general practice. Med J Aust. 2011;194(5):16-19.

26. Liberati EG, Gorli M, Scaratti G. Invisible walls within multidisciplinary teams: disciplinary boundaries and their effects on integrated care. Soc Sci Med. 2016;150:31-39. http://dx.doi.org/10.1016/j.socscimed.2015.12.002.

27. Hartgerink JM, Cramm JM, Bakker TJEM, Van Eijsden AM, Mackenbach JP, Nieboer AP. The importance of multidisciplinary teamwork and team climate for relational coordination among teams delivering care to older patients. J Adv Nurs. 2014;70(4):791-799. http://dx.doi.org/10.1111/jan.12233.

28. Bodenheimer T, Wagner E, Grumbach K. Improving primary care for patients with chronic illness. J Am Med Assoc. 2002;288(14):1775-1779. http:// dx.doi.org/10.1001/jama.288.14.1775. 